
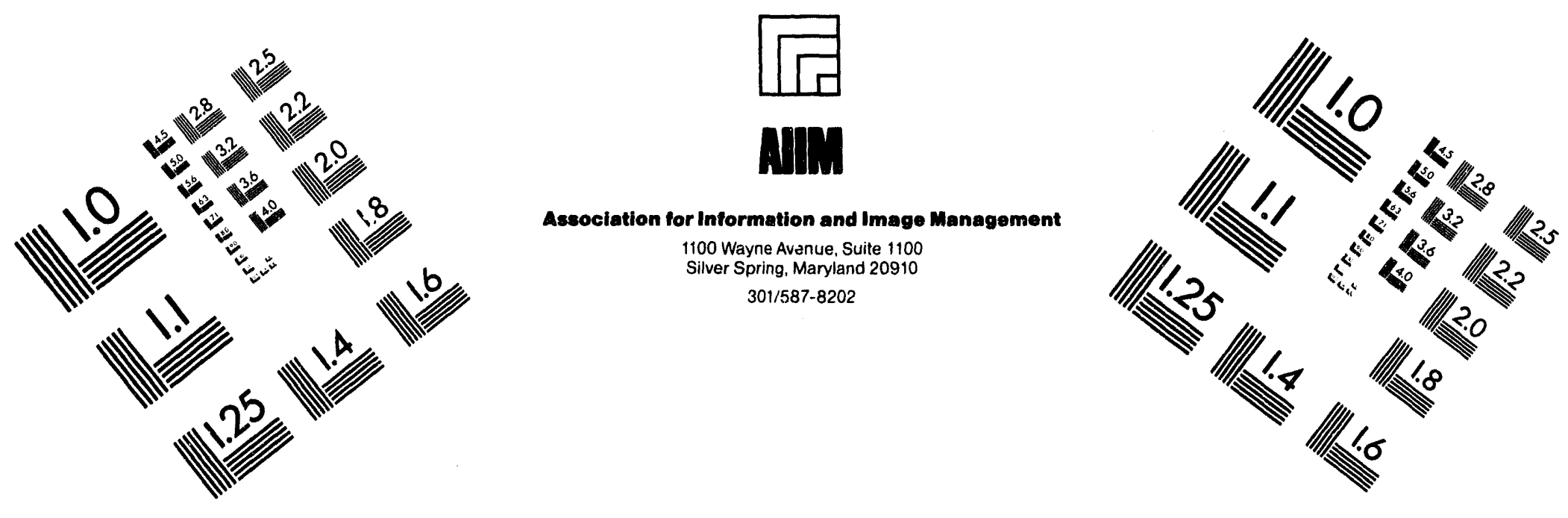

Centimeter

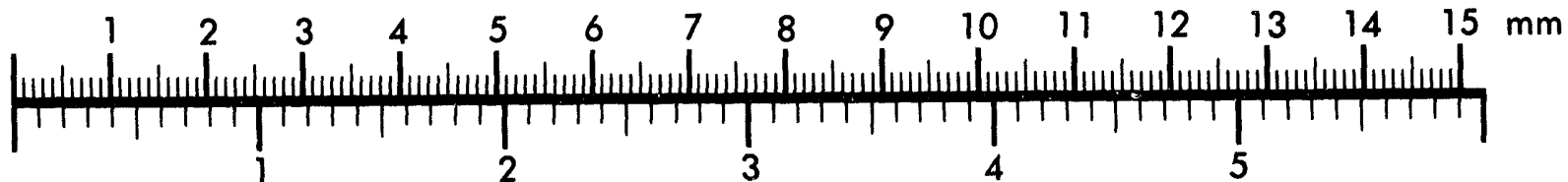
Inches
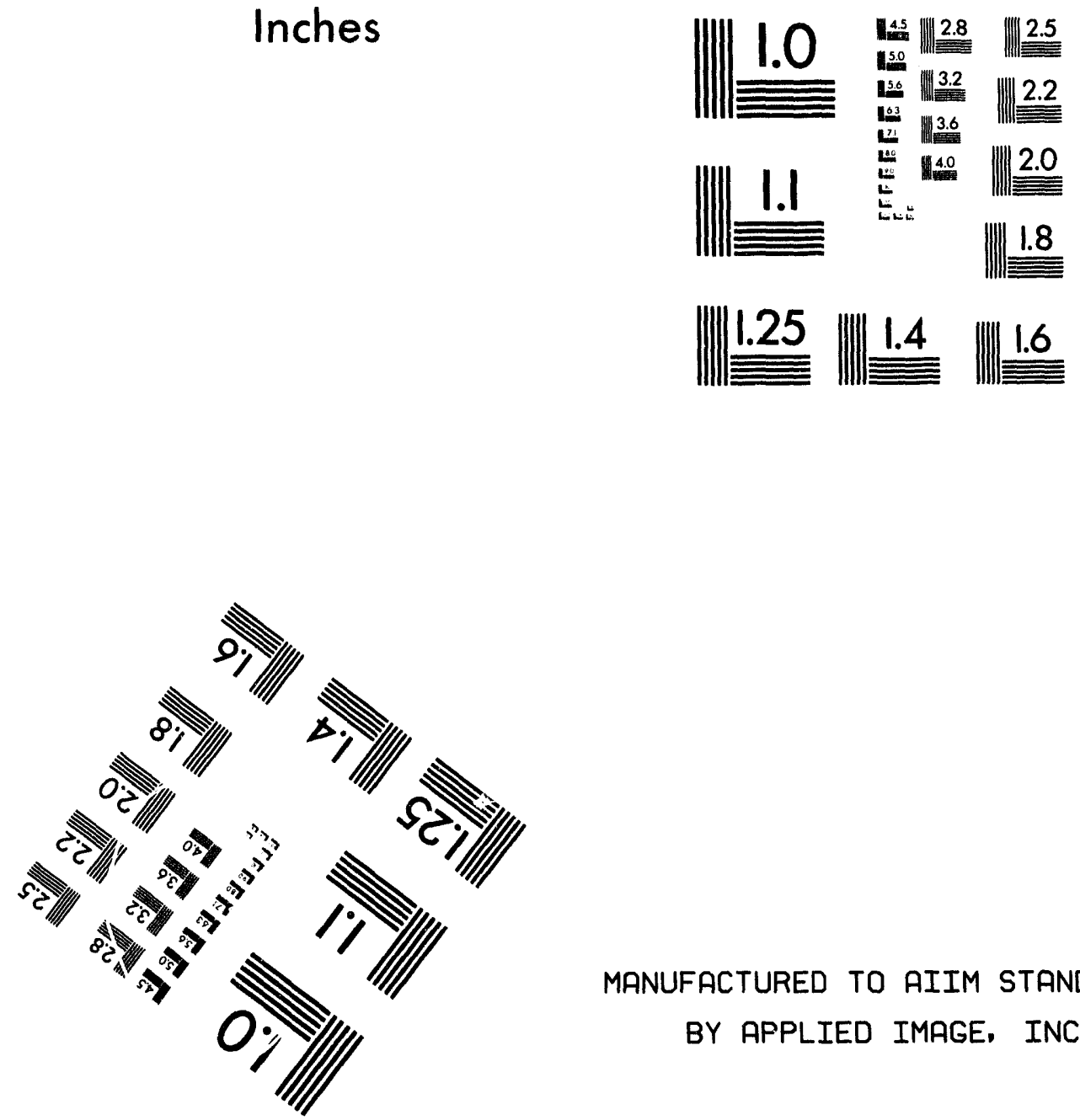

MANUFACTURED TO AIIM STANDARDS

BY APPLIED IMAGE, INC.

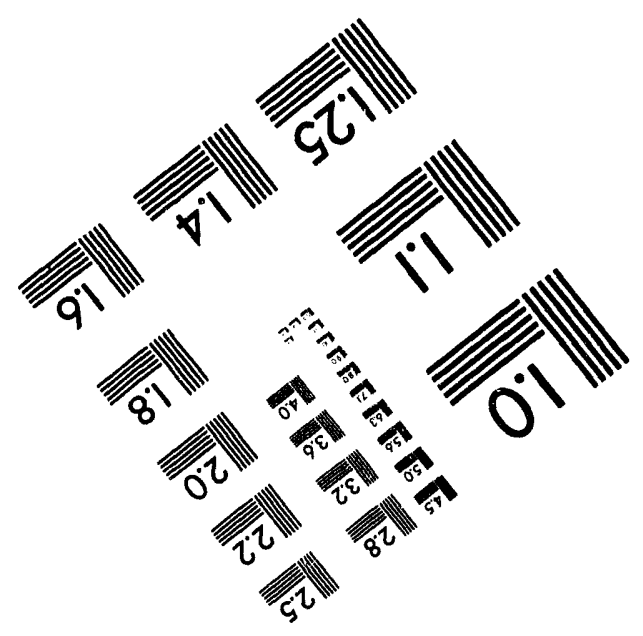



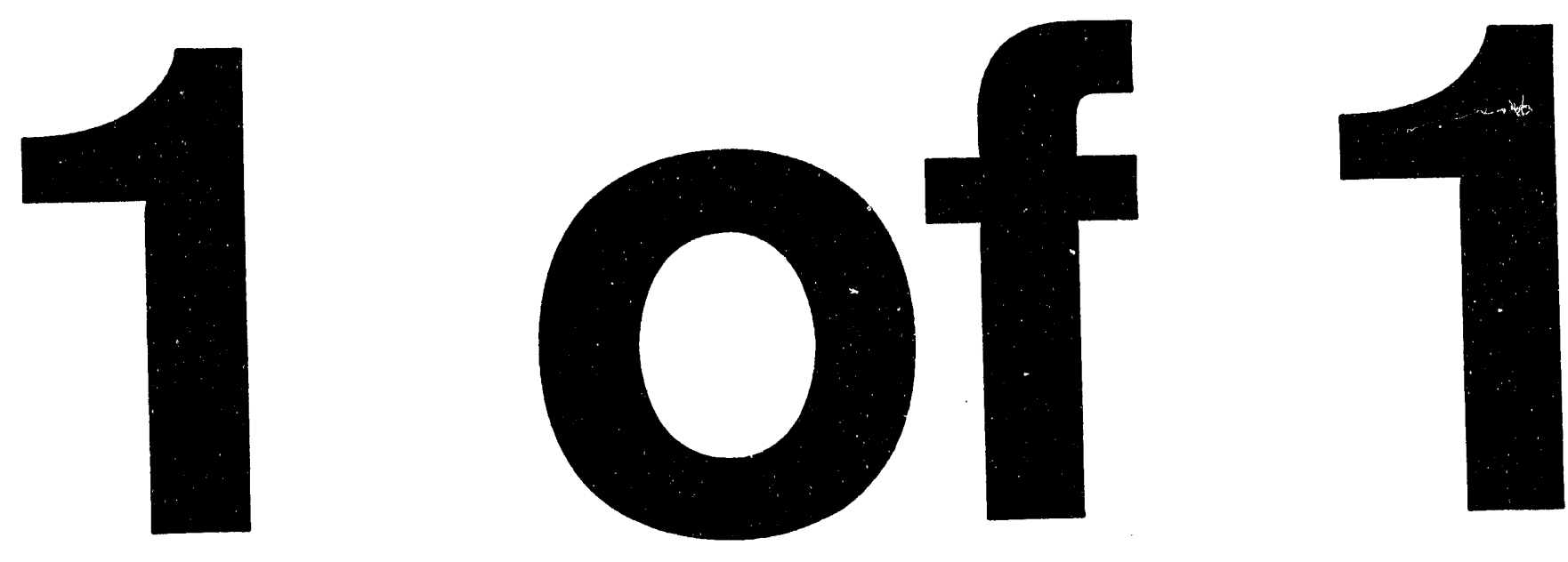


\title{
ETHANOL SYNTHESIS AND WATER GAS SHIFT OVER BIFUNCTIONAL SULFIDE CATALYSTS
}

\begin{abstract}
Disclaimer
This report was prepared as an account of work sponsored by the United States Government. Neither the United States nor the United States DOE, nor any of their employees, nor any of their contractors, subcontractors, or their employees, makes any warranty, express or implied, or assumes any legal liability or responsibility for the accuracy, completeness, or usefulness of any information, apparatus, product or process disclosed, or represents that its use would not infringe privately owned rights.
\end{abstract}

\section{DISCLAIMER}

\begin{abstract}
This report was prepared as an account of work sponsored by an agency of the United States Government. Neither the United States Government nor any agency thereof, nor any of their employees, makes any warranty, express or implied, or assumes any legal liability or responsibility for the accuracy, completeness, or usefulness of any information, apparatus, product, or process disclosed, or represents that its use would not infringt privately owned rights. Reference herein to any specific commercial product, process, or service by trade name, trademark, manufacturer, or otherwise does not necessarily constitute or imply its endorsement, recommendation, or favoring by the United States Government or any agency thereof. The views and opinions of authors expressed herein do not necessarily state or reflect those of the United States Government or any agency thereof.
\end{abstract}




\section{ETHANOL SYNTHESIS AND WATER GAS SHIFT OVER BIFUNCTIONAL SULFIDE CATALYSTS}

\section{SUMMARY OF TECHNICAL PROGRESS}

During this quarter, the cesium formate-doped and the undoped molybdenum disulfide previously prepared were sent out to Galbraith Laboratories for elemental analysis for cesium, molybdenum, and sulfur. A new Na/ $\mathrm{MoS}_{2}$ catalyst was prepared under an inert atmosphere by an intercalation technique using sodium metal dissolved in liquid ammonia. This sample will be fully characterized. An all-glass apparatus was constructed for carrying out systematic intercalation procedures with alkali metals dissolved in liquid ammonia. This apparatus will insure that the dispersed catalysts are prepared in an oxygen/moisture-free environment. The stainless steel continuous flow high pressure/high temperature catalyst testing system was rebuilt and the analytical end of the unit was upgraded. 


\section{ETHANOL SYNTHESIS AND WATER GAS SHIFT OVER BIFUNCTIONAL SULFIDE CATALYSTS TECHNICAL PROGRESS}

Both the fresh cesium formate-doped and fresh undoped molybdenum disulfide that were prepared last quarter were sent to Galbraith Laboratories. The \%wt of each analyzed element in the sample is given in Table I. This gives $\mathrm{MoS}_{2.00}$ for the undoped catalyst and $12.89 \mathrm{wt} \% \mathrm{CsOOCH} / \mathrm{MoS}_{1.92}$ for the fresh doped sample. Elemental analysis on the used catalyst has yet to be done.

Table I.

\begin{tabular}{|c|c|c|c|}
\hline ELEMENT(wt\%) & CESIUM & MOLYBDENUM & SULFUR \\
\hline $\mathrm{MoS}_{2}$ & N/A & 57.34 & 38.33 \\
\hline $\mathrm{Cs} / \mathrm{MoS}_{2}$ & 9.63 & 50.26 & 32.28 \\
\hline
\end{tabular}

A preliminary intercalation experiment was carried out wherein sodium metal dissolved in liquid ammonia was dispersed into $\mathrm{MoS}_{2}$. This preparation was carried out in a glove bag with an inert atmosphere, and the catalyst sample is being characterized.

Preparation has been made to prepare a $\mathrm{MoS}_{2}$ catalyst that will contain dispersed intercalated alkali metal. Figure 1 shows the glass apparatus that was constructed to complete the different doping procedure that will be carried out in the absence of air. What is envisioned is that liquid ammonia will be further purified by the freeze-pump-thaw technique in flask $\mathrm{A}$ two times. The liquid ammonia will then be vacuum transferred to flask B which will contain the alkali metal (Cs) that will be used to dope $\mathrm{MoS}_{2}$. The alkali 
metal dissolved in ammonia will be released into vessel $\mathrm{C}$ that will contain the molybdenum disulfide on a fritted glass filter. After equilibrium for approximately $24 \mathrm{hr}$ at dry ice/acetone temperature, the liquid ammonia/alkali metal solution will be filter off into flask $\mathrm{D}$. The alkali intercalated $\mathrm{MoS}_{2}$ will be washed several times with liquid ammonia and then evacuated at $50^{\circ} \mathrm{C}$. The resultant catalyst will then be loaded into a reactor under argon and catalytic behavior will be evaluated.

The stainless steel downflow continuous operation catalyst testing system that is utilized for testing catalysts at high pressure, e.g. 8.2 $\mathrm{MPa}$, and high temperature, e.g. 250$325^{\circ} \mathrm{C}$, has been rebuilt. 


\section{FIGURE 1. DOPING APPARATUS}

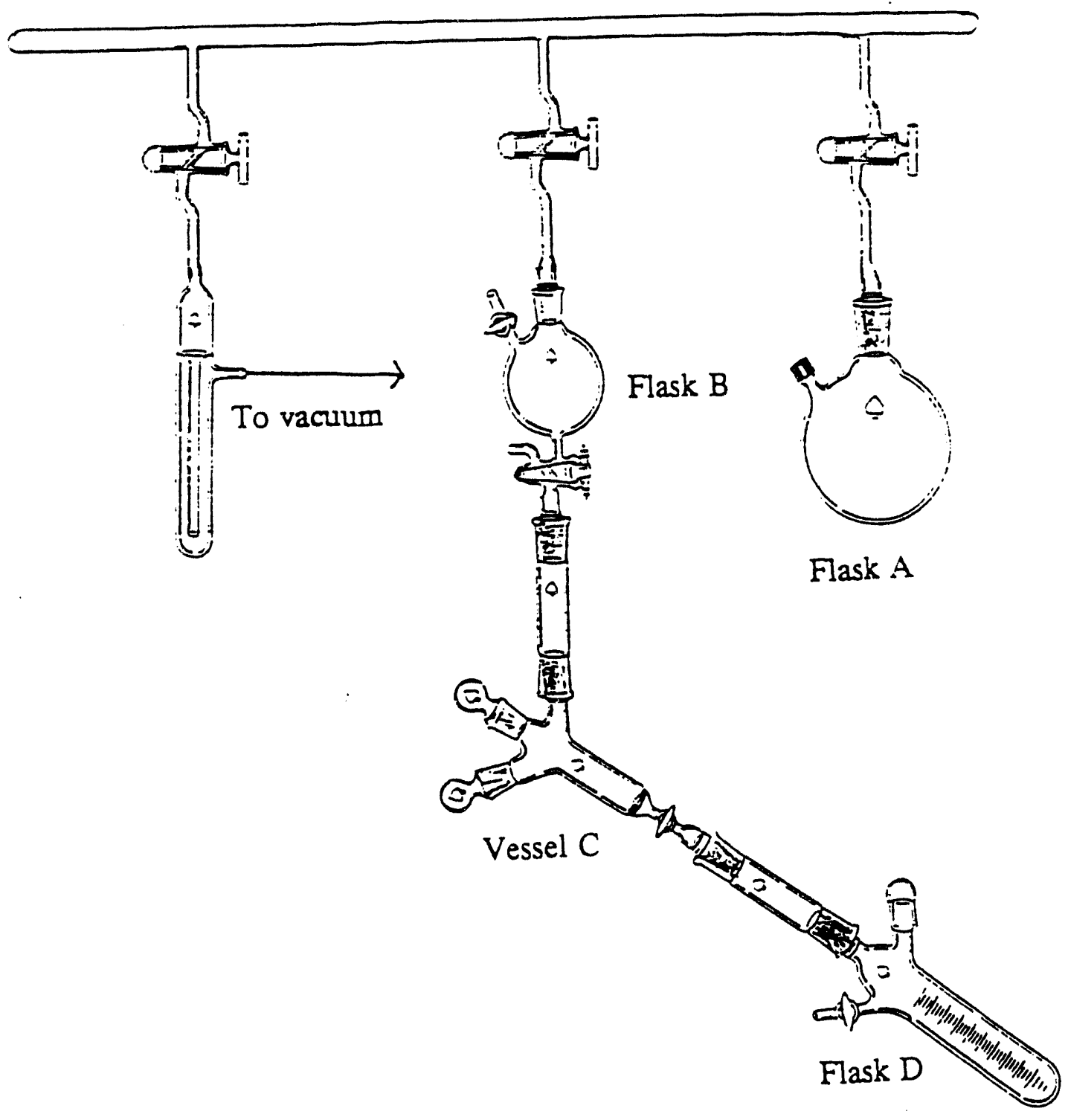



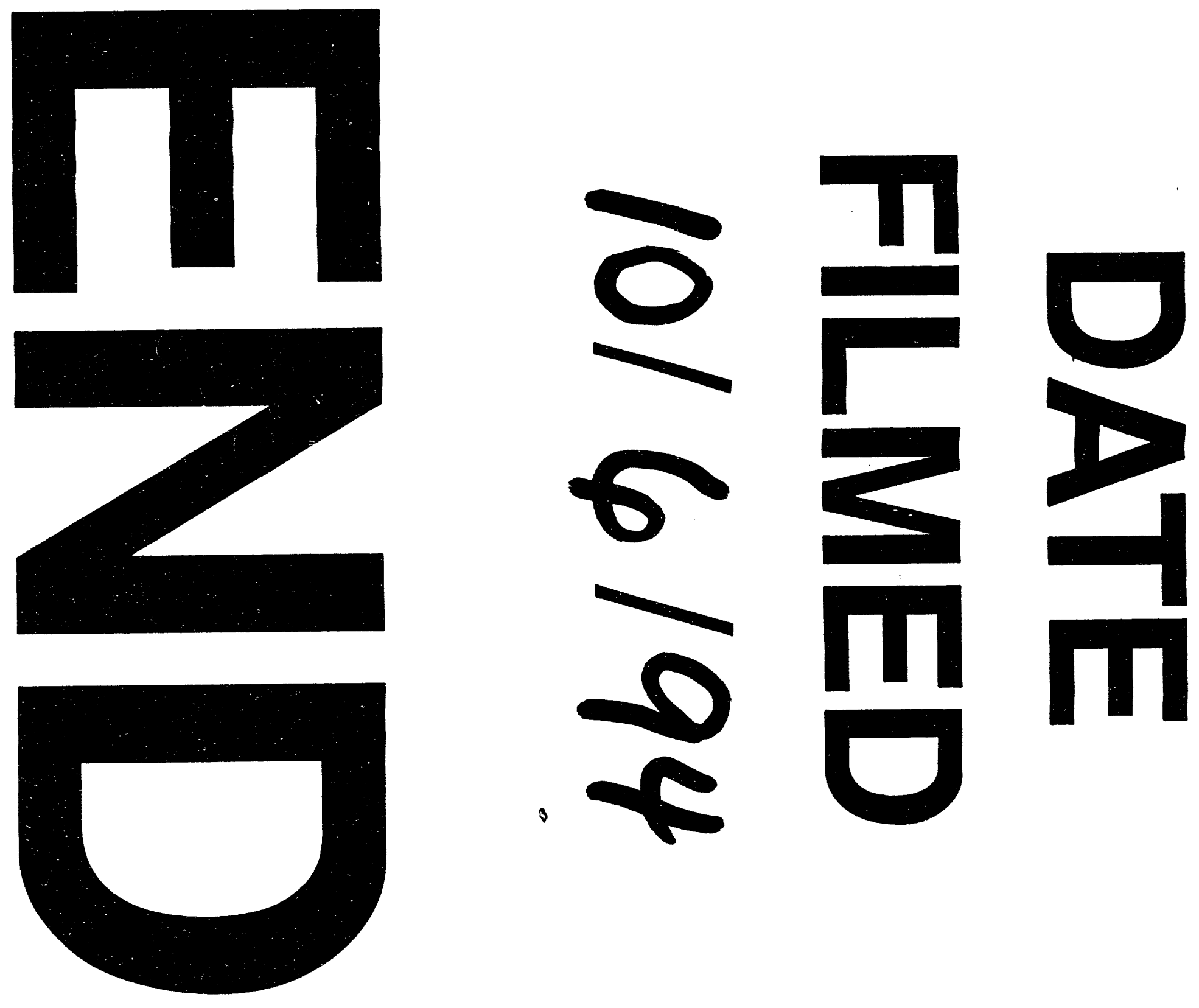
